
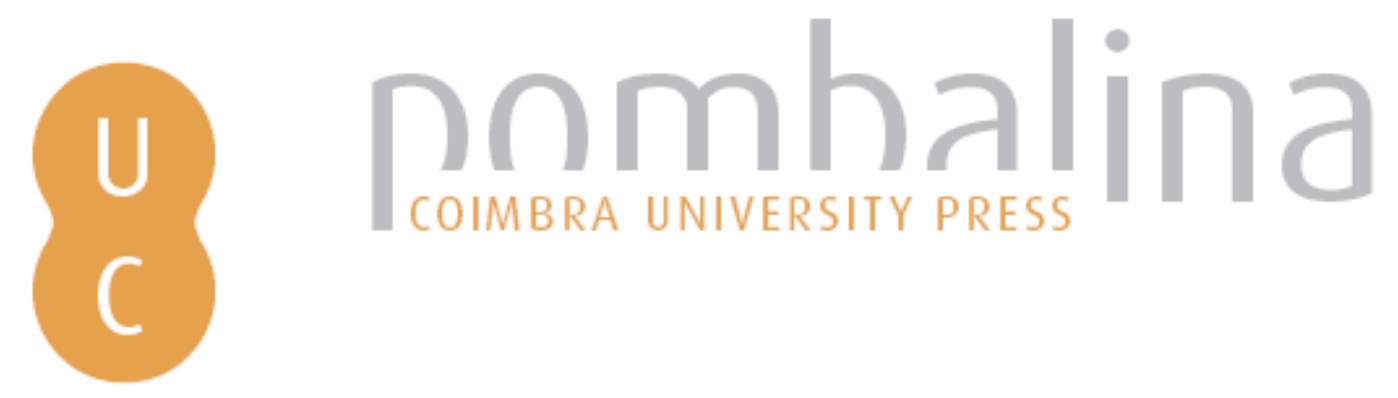

\title{
A democracia vai crescer ou diminuir?
}

\author{
Autor(es): $\quad$ Ribeiro, Renato Janine
}

Publicado por: Imprensa da Universidade de Coimbra

URL

persistente: URI:http://hdl.handle.net/10316.2/43158

DOI: $\quad$ DOl:https://doi.org/10.14195/978-989-26-1433-5_3

Accessed : $\quad$ 26-Apr-2023 16:17:45

A navegação consulta e descarregamento dos títulos inseridos nas Bibliotecas Digitais UC Digitalis, UC Pombalina e UC Impactum, pressupõem a aceitação plena e sem reservas dos Termos e Condições de Uso destas Bibliotecas Digitais, disponíveis em https://digitalis.uc.pt/pt-pt/termos.

Conforme exposto nos referidos Termos e Condições de Uso, o descarregamento de títulos de acesso restrito requer uma licença válida de autorização devendo o utilizador aceder ao(s) documento(s) a partir de um endereço de IP da instituição detentora da supramencionada licença.

Ao utilizador é apenas permitido o descarregamento para uso pessoal, pelo que o emprego do(s) título(s) descarregado(s) para outro fim, designadamente comercial, carece de autorização do respetivo autor ou editor da obra.

Na medida em que todas as obras da UC Digitalis se encontram protegidas pelo Código do Direito de Autor e Direitos Conexos e demais legislação aplicável, toda a cópia, parcial ou total, deste documento, nos casos em que é legalmente admitida, deverá conter ou fazer-se acompanhar por este aviso. 


\section{Euro-Atlântico:}

\section{Espaço de Diálogos}

Isabel Maria Freitas Valente

Iranilson Buriti de Oliveira

(Coord)

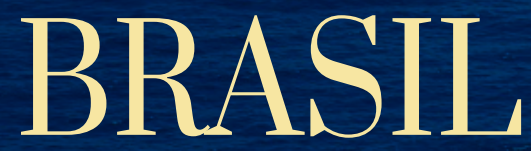

NAS ONDAS

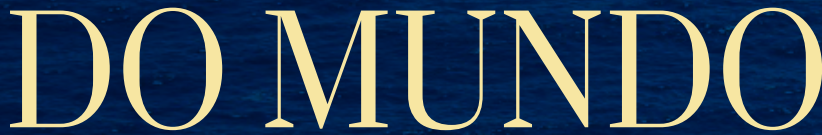

Álvaro Vasconcelos (Org)

Editora da Universidade Federal de Campina Grande

Imprensa da Universidade de Coimbra

2017 


\section{A DEMOCRACIA VAI CRESCER OU DIMINUIR?}

Renato Janine Ribeiro, $\mathrm{PhD}$ USP, Departamento de Filosofia, FFLCH

E-mail:rjanine@usp.br

\section{Resumo}

Depois da intensa democratização da política e da vida social ocorrida nas últimas décadas, estaremos chegando a seu limite - ou mesmo a um recuo do que imaginávamos ser irreversível? O artigo discute a possibilidade de um recuo democrático, levando em conta tanto o que aconteceu no mundo (Brexit, Trump) quanto os acontecimentos políticos brasileiros desde 2013.

Palavras-Chave: Democracia; Brexit; Trump; Brasil

\section{Abstract}

After some decades of intense democratization of both political and social lives all around the world, is it possible that we are witnessing its limits or even a retreat from what we took for granted? The paper discusses the possibilities of a downgrade both in political and social democracy, considering what happened in the world (Brexit, Trump) and most of all in Brazilian politics since 2013.

Keywords: Democracy; Brexit; Trump; Brazil 
A democracia vai continuar se expandindo, a ponto de em algumas décadas ou quando muito até o final do século XXI tornar-se o regime em que viverá o mundo inteiro - abrindo talvez perspectivas inéditas para a paz mundial sonhada por Kant - ou terá chegado a seu teto e, de agora em diante, há de recuar? Discutiremos aqui dois cenários possíveis, globais e brasileiros, para o futuro da democracia. Em alguns momentos o texto se concentrará na política brasileira, mas o enfoque é sempre global, e a pergunta crucial - se, primeiro, a democracia chegou a seu teto; se, segundo, começará a recuar ou se, terceiro, continuará a contaminar positivamente com seus valores não só a vida política, mas também a social e a econômica de nosso mundo - aplica-se ao mundo inteiro. É difícil dizer qual cenário parece, hoje, mais provável. Por isso mesmo, é honesto apresentar as possibilidades que temos diante de nós.

Nos três séculos e pouco que transcorreram desde as três grandes Revoluções (Inglesa, Americana, Francesa), o teor de democracia no mundo aumentou sensivelmente - embora conhecendo retrocessos às vezes assustadores, como nas décadas de 1920 e 1930. No tempo de Péricles, a Atenas democrática representava talvez $0,1 \%$ da população mundial. Já se conferimos o Índice da Democracia que todo ano The Economist publica, $49,3 \%$ da população do planeta vivia em democracias em 2016, somando as plenas (full democracies) e aquelas que, com exagero, a revista diz que têm falhas (flawed democracies) - representando uma expansão em relação a 2014, quando eram 48\%; uma expansão pequena, de apenas 1,3\%, mas que aproxima o número dos viventes em democracias da maioria da população mundial. Num mix que reúne cinco critérios - o processo eleitoral e seu pluralismo, o funcionamento do governo, a participação política, a cultura política e as liberdades civis - 19 países obtêm nota entre 8,17 e 9,93, a mais elevada, com um total de 4,5\% da população mundial, sendo esses os que a Economist Intelligence Unit caracteriza como democracias plenas (eram 24 em 2014 e cobriam um oitavo da população mundial). Entre eles temos a Noruega, em primeiro lugar, junto com vários países nórdicos, e uma maioria de Estados do core inicial 
da OTAN, entre eles Canadá, Alemanha, Reino Unido e Espanha, sendo que fora desse espaço norte-atlântico apenas comparecem os antigos domínios britânicos da Oceânia e as ilhas Maurício; já na América Latina e Caribe, somente o Uruguai. Entre as democracias plenas rebaixadas a democracias com falhas figuram Estados Unidos, França, Japão, Coreia do Sul e Costa Rica: isso significa, o que é quase chocante, que duas das democracias históricas, aquelas que deram nome às grandes revoluções do século XVIII, a Americana e a Francesa, caíram do primeiro para o segundo escalão dos regimes democráticos. Mais grave ainda é o fato de que o número de cidadãos em democracias plenas tenha passado de $12,5 \%$ para $4,5 \%$ da população mundial, sofrendo um corte de quase dois terços. Essa estatística indica bem a dimensão do problema que nos colocamos no começo: a democracia terá cessado sua expansão? Estará recuando no mundo?

Pelos mesmos critérios, os 57 países seguintes - as democracias com falhas - congregam $44,8 \%$ dos habitantes da Terra (eram 52 países em 2014, reunindo 35,5\% da humanidade). O Japão, com nota 7,99, e os Estados Unidos, com 7,98, encabeçam o pelotão, que termina com a Moldova (6,01). O Brasil recebe 6,90, contra 7,38 dois anos antes - uma bela queda. Nessa listagem estão alguns grandes países como a Índia, África do Sul, Brasil, Indonésia e México. Esse segundo rol me parece mais duvidoso. Entre esses países, estão alguns que reprimem, de maneira até mesmo brutal, a dissidência política - a par de nações que, mesmo enfrentando problemas, justificados no caso da vitória de Trump nos Estados Unidos, não chegam porém a validar o rebaixamento, como o da França. Aliás, em alguns casos, a preferência ideológica da revista pela empresa privada se torna mais decisiva do que o efetivo respeito ao que é democrático, submetendo esse conceito ao prisma parcial do liberalismo econômico. De todo modo, o adjetivo inglês flawed é exagerado, porque designa falhas demasiado grandes, o que não é o caso da maior parte destes países. 
Seja como for, mesmo que a soma das democracias plenas e das falhas tenha incluído mais $1,3 \%$ da população humana nos regimes mais (ou menos) democráticos, o fato é que caiu o teor de democracia em muitos países. Continua sendo válido considerar que em torno de metade da população mundial hoje vive em regimes que respeitam as liberdades políticas e pessoais. (Dificilmente existe uma sem a outra). No período iniciado na década de 1980, caíram as ditaduras de direita na América Latina e as de esquerda na Europa Oriental, o que repercutiu na África e na Ásia, abrindo uma era em que, pela primeira vez, a quase maioria do mundo vive em regimes que respeitam liberdades pessoais e direitos políticos.

Além do avanço quantitativo, ocorreu um qualitativo: as democracias existentes não são democráticas só por reconhecerem o direito de voto à grande maioria da população, mas por respeitarem os direitos humanos - que vão se ampliando, seja graças a ações da ONU, como a aprovação em 1959 da Declaração Universal dos Direitos das Crianças e em 1996 da Declaração de Istambul sobre o Direito à Moradia, seja em decorrência de movimentos sociais empenhados. O conceito de democracia foi-se tornando cada vez mais exigente.

Mas a pergunta é se essa "terceira onda" democratizante, para retomar a expressão de Samuel Huntington em seu livro de 1991, parou de vez ou se pode retomar seu ímpeto. (Empregamos o termo de Huntington, mas mudamos seu sentido, entendendo a democracia como não apenas política, mas social). Na década de 2010, e em especial desde o Brexit, a eleição de Trump e num plano menor o impeachment no Brasil, fatos de 2016, os grupos contrários às liberdades tanto políticas quanto pessoais avançaram de forma antes imprevista. Não é apenas um deslizamento para a direita, por exemplo, como na América do Sul. É o reforço da xenofobia, da homofobia, do fundamentalismo nos três grandes monoteísmos, da misoginia em todos os continentes - para não mencionar o retorno da tendência, em vários países, a considerar o adversário político como inimigo merecedor de ser reprimido. Isso coloca a democracia sob ameaça. 
As mudanças na Previdência Social, que ocorrem em democracias ditas plenas assim como nas falhas, não ajudam. Mesmo se justificando por uma dificuldade de custear as pensões por idade, elas têm um impacto duro sobre a percepção, pelos mais pobres, de seus direitos. Direitos não são apenas abstratos: incluem a expectativa ou a esperança de um final de vida tranquilo e que preserve a qualidade da vida que se teve durante os anos em que se trabalhou, o que parece tornar-se mais difícil para os anos vindouros. Essa também é uma ameaça, se não à democracia, pelo menos à confiança nesse regime.

No Brasil, houve uma certa ironia. Os movimentos de 2013 nas ruas, imprevistos apenas alguns dias antes de ocorrerem, clamavam por um transporte público melhor e se espraiaram para a exigência de educação e saúde "padrão FIFA", em alusão às Copas de Futebol que teriam lugar aquele ano e no seguinte. Contudo, desde o impeachment da presidente Dilma Rousseff, em 2016, as medidas anunciadas pelo novo governo reduziram os investimentos sociais, de modo que a esperança em educação, saúde, transporte e segurança de qualidade cada vez se justifica menos. As ruas, tomadas em 2013 por grupos autônomos à esquerda do governo, foram depois ocupadas por manifestantes antipetistas, que viam na corrupção, supostamente apenas do PT, a raiz dos males do país; o problema é que, com isso, o padrão FIFA parece cada vez mais longínquo. Mesmo as conquistas, ainda que insuficientes, em inclusão social estão em risco de serem revertidas.

O impeachment foi aprovado com escassa base jurídica. Para destituir a presidente, a direita democrática aceitou subordinar-se à direita comportamental, ou extrema-direita, e aos políticos mais acusados de corrupção no país. Já em 12 de abril de 2015, data de passeatas pró-impeachment, a cientista política Mara Telles, da UFMG, em pesquisa com 90 perguntas feita entre manifestantes, constatou uma posição deles significativamente à direita, em vários casos exprimindo preconceitos 
contra pobres e nordestinos ou contra todos os partidos políticos ${ }^{36}$. Não se trata de negar o legítimo direito de protestar - mas de notar que levantava a cabeça, pela primeira vez em vários anos, uma forte resistência a direitos sociais que, em países mais desenvolvidos, são ou eram incontestáveis. Pior, a defesa de tais direitos - há muito reconhecidos nas três democracias fundantes, que são Reino Unido, Estados Unidos e França, bem como nas sólidas Alemanha e Escandinávia - aparecia aos olhos dos conservadores brasileiros como emanando de Cuba ou Venezuela.

Um parêntese aqui. Apresentei, em trabalhos anteriores ${ }^{37}$, as manifestações de 2013 como abrindo uma nova fase na democracia brasileira. Sustento que desde 1985 tivemos três agendas democráticas, e que os protestos de 2013 abriram uma quarta. Essas agendas tiveram alguns pontos em comum: um, surgiram como reivindicações de apenas uma parte da sociedade, enfrentando o descaso ou mesmo rejeição da maior parte dos atores com poder de decisão; dois, demoraram a se implantar; três, cada uma delas teve um partido a liderá-la, ou desde o começo ou depois de sua adoção; quatro, tornaram-se finalmente políticas de Estado, sendo que hoje nenhum candidato ao Poder Executivo contesta nenhuma delas, sob pena de ser relegado à insignificância. Assim tivemos, como primeira agenda, a democratização das instituições, que venceu em 1985 e foi crescendo desde então, após 21 anos de ditadura com graus variáveis de repressão, tendo sido comandada pelo PMDB. A segunda agenda foi a do combate à inflação, efetivado pelo Plano Real, em 1994, após décadas de erosão da moeda, sendo apropriada $a$ posteriori pelo PSDB. Já a terceira foi a da inclusão social como política de Estado, implantada a partir de 2003 pelo PT, isso depois de quase cinco séculos de opressão social (desde o começo da colonização, na década de 1530) e mais de quatro séculos de resistência (desde 1580,

\footnotetext{
${ }^{36}$ Ver a pesquisa completa em Perfil Ideológico e Atitudes Políticas dos Manifestantes. Belo Horizonte, 12 de abril de 2015.

37 Ver meu "Brazil and the democracy of protest", 2014.
} 
data provável da fundação do quilombo dos Palmares). Enquanto as duas primeiras agendas conseguiram um sucesso acima do razoável, a terceira - e mais importante -, por afrontar a estrutura mesma, iníqua, da sociedade brasileira, ficou incompleta e, desde 2015, está recuando, no final do governo Dilma devido à crise econômica, e no governo atual também pelo pouco interesse do mesmo por estas causas.

Chamo de quarta agenda a defesa de serviços públicos de qualidade. É o que falta à democracia brasileira - bem como a conclusão da terceira agenda, a da inclusão social. Sustento que, no Brasil, a classe média (termo que não é um conceito preciso, sendo mais da ordem do desejo do que da descrição seca) se distingue por atingir uma dignidade, por vezes ilusória, que se caracteriza antes de mais nada negativamente: ela não usa os transportes públicos, a educação pública, a saúde pública nem a segurança pública, substituindo-os pelo carro particular, as escolas privadas, o plano de saúde e o segurança do condomínio ou da rua. Ora, essa classe média, antiga e mais conservadora, ou nova e mais "batalhadora" (para empregar o termo introduzido na análise desse fenômeno por Jessé Souza), já não aceita pagar impostos em troca de serviços insuficientes. Daí, a meu ver, a revolta de 2013, que não por acaso começou com o protesto pelo transporte público gratuito (bandeira levantada pelos grupos mais à esquerda) e ao se generalizar lhe juntou o clamor pela educação e saúde públicas de qualidade ${ }^{38}$. O insucesso dessa agenda a curto prazo, até porque esta é a primeira agenda que não encontrou partido, programa claro ou liderança, alimentou os protestos de teor muito conservador de março de 2015 até o impeachment de Dilma, em abril de 2016. Tão logo a presidente conseguiu a reeleição, em outubro de 2014, após uma disputa renhida com o candidato Aécio Neves, do PSDB, iniciou-se a deslegitimação de seu mandato, com

38 É certo que também se protestou contra a corrupção, e além disso contra a rede Globo, sendo que este último protesto foi escassamente noticiado na televisão, rádio e imprensa. 
ações no Judiciário pedindo uma bizarra recontagem de votos (o que num sistema que utiliza há muitos anos as urnas eletrônicas fica entre desnecessário e impossível), seguidas de protestos nas ruas, campanhas na imprensa e estímulo da mídia ao impeachment. Embora a presidente substituísse a política econômica de seu governo, antes heterodoxa, por uma ortodoxa, não conseguiu apoio no Congresso para suas propostas legislativas, agravando-se a crise na economia. Finalmente, seus próprios aliados, incluindo seu vice-presidente, a abandonaram e, quando foi afastada, formou-se um governo que implementou as medidas que, para o bem ou o mal, tinham sido derrotadas nas urnas menos de dois anos antes. Como ao mesmo tempo cada vez mais políticos - sobretudo do novo governo - foram sendo acusados de corrupção na Justiça, resultou disso um grande desencanto popular com a política e os políticos, com efeitos preocupantes para o futuro da democracia brasileira.

\section{$* * *$}

A questão é: esses sinais preocupantes são apenas um soluço derradeiro, numa humanidade que continuaria sua marcha "tocquevilliana" rumo à igualdade, às liberdades, à democracia - ou constituem um ponto final nessa trajetória? Se colocássemos esta questão em 1935 ou 1940, como muitos de fato a colocaram àquela época, possivelmente tenderíamos a cravar a segunda opção. Com efeito, no plano dos valores políticos, a oposição entre fascismo e stalinismo tornava exíguo o espaço para a democracia que, além disso, ao ser apenas liberal, ao ser indiferente às questões sociais, não despertava o apoio das massas. O Estado liberal após o massacre da Grande Guerra, que afetou dezenas de milhões de pobres ou empobrecidos, mutilados, órfãos, viúvas - não sentiu que lhe coubesse aliviar o fardo dessas vítimas. A ideia de usar a tributação para que a sociedade pagasse as perdas dos diretamente prejudicados mal foi considerada, sendo esta uma das grandes razões para o progresso dos totalitarismos nas décadas de 1920-30 (em compensação, a ideia de 
empregar os impostos para proteger os afetados pela loteria negativa da guerra será uma das primeiras medidas de Churchill, primeiro-ministro em 1940, por ocasião dos bombardeios nazistas a Londres).

Depois da guerra, as democracias foram além do liberalismo, adotando um compromisso social com as vítimas do viver coletivo que até pode variar conforme o país, mas tende a ser significativo. A democracia ganhou um appeal popular bem maior. Foi muito além da democracia liberal. Em que pese o recuo dos partidos social-democratas depois dos Trinta Anos Gloriosos, vários traços que eles introduziram acabaram caracterizando a própria democracia, sobretudo na Europa. Mesmo os liberais evitaram associar-se demais ao antigo liberalismo, avesso que ele era a todo compromisso social.

Um exemplo importante de sucesso social-democrático está nos programas de inclusão social que se espalharam pelo mundo, a exemplo do Bolsa Família (BF) brasileiro e várias vezes tomando-o como exemplo. Contudo, é bom frisar que o BF teve um papel relevante - e principalmente visível - nos primeiros anos de gestão do PT; o legado mais consistente em termos de inclusão social consistiu no aumento real do salário mínimo, que se elevou muito em termos reais. ${ }^{39}$ Estudos acadêmicos mostraram o papel positivo do BF no empowerment das camadas mais pobres, por ele atendidas. Evidentemente, essa inclusão social tem efeitos benéficos sobre a participação na política.

E no entanto, depois disso, chegamos a uma situação que, sob alguns aspectos, lembra o entre-guerras. Preconceitos dos mais variados tipos -

39 É interessante, porém, que o foco se coloque no BF. Este programa foi criticado pela oposição porque não teria "porta de saída" ou exigências para nele permanecer (tem algumas, como a mulher grávida fazer o acompanhamento médico durante a gestação). Chegou a ser acusado de ser uma esmola ou de ter um caráter eleitoreiro. Contudo, nas eleições de 2010 e sobretudo 2014 os candidatos do PSDB, respectivamente José Serra e Aécio Neves, prometeram, o primeiro, aumentá-lo, o segundo, convertê-lo em política de Estado (o que na verdade já é). O que faltou ao candidato Aécio foi perceber que o BF já estava em segundo plano perante o aumento real do salário mínimo - aumento esse que Aécio e seu possível ministro da Fazenda, Armínio Fraga, disseram durante a campanha que não poderiam continuar promovendo, em decorrência do estado da economia. 
contra o estrangeiro (na Europa), contra o imigrante ilegal (nos Estados Unidos), contra os miseráveis e em especial os mais vulneráveis sociais, como os travestis, bem como a islamofobia 40 - aparecem em público e às vezes até no discurso político. Movimentos especificamente voltados contra os direitos humanos, que sempre existiram mas pareciam estar com o crescimento contido, se fortaleceram. O que esperar desse quadro sombrio? O que podemos fazer para evitar esse roteiro preocupante, ainda mais porque marcado por um avanço sectário, em termos religiosos, que substitui o debate pelo anátema?

Voltemos um pouco ao Brasil. A Constituição de 1988 foi a primeira em nossa História a substituir a declaração de princípios com que desde 1934 começam nossas Cartas - "todo poder emana do povo e em seu nome será exercido” ${ }^{41}$, uma apologia da democracia desde que representativa - por uma proclamação que inclui a democracia direta: "Todo o poder emana do povo, que o exerce por meio de representantes eleitos ou diretamente, nos termos desta Constituição." (art.1 ${ }^{\circ}$, par. único). Contudo, a democracia direta se exerceu de forma tímida. Apenas quatro leis, em 25 anos, foram aprovadas pelo Congresso a partir da iniciativa popular, quando $1 \%$ do eleitorado submete um projeto ao Legislativo, caso em que a coleta de assinaturas constitui um instrumento poderoso de mobilização. Dessas leis, duas se referiam ao processo político - a lei

40 Penso aqui na decisão da prefeitura de São Paulo, na gestão Haddad (PT, 20132016), de dar uma bolsa aos travestis para que possam estudar e sair da contravenção.

41 1934: "Art $2^{\circ}$ - Todos os poderes emanam do povo e em nome dele são exercidos."

1937, Carta da ditadura Vargas: "Art $1^{\circ}$ - O Brasil é uma República. O poder político emana do povo e é exercido em nome dele e no interesse do seu bem-estar, da sua honra, da sua independência e da sua prosperidade."

1946: "Art $1^{\circ}$ - Os Estados Unidos do Brasil mantêm, sob o regime representativo, a Federação e a República./ Todo poder emana do povo e em seu nome será exercido."

1967, Carta da ditadura militar: "Art. $1^{\circ}$, par. $1^{\circ}-\S 1^{\circ}$ - Todo poder emana do povo e em seu nome é exercido."

1969, Carta outorgada pela Junta Militar: "Art. $1^{\circ}, \S 1^{\circ}$ Todo o poder emana do povo e em seu nome é exercido."

Diferenças de redação ("todo poder" significando qualquer poder, "todo o poder" no sentido do poder inteiro) não parecem ser essenciais, mostrando apenas características de estilo. 
contra a compra de votos por candidatos e a lei Ficha Limpa -, uma à habitação popular e outra à punição de crimes hediondos ${ }^{42}$. A iniciativa popular também se expressou num plebiscito e num referendo. O plebiscito teve lugar em 21 de abril de 1993, por mandamento constitucional, e submeteu ao eleitorado a escolha bizarra, anacrônica, entre monarquia e república, com $86,6 \%$ dos eleitores preferindo a segunda, e a mais séria, entre parlamentarismo e presidencialismo, com 69,2\% optando por este último ${ }^{43}$. Já o referendo ocorreu em 23 de outubro de 2005 e questionava se entraria ou não em vigor a proibição, inicialmente aprovada pelo Congresso, de comercialização de armas de fogo. Com quase $64 \%$ de votos negativos, a proibição foi derrotada.

Um balanço desses seis episódios de democracia direta é decepcionante. A primeira lei de iniciativa popular, agravando a punição a crimes hediondos, respondia à indignação com o recente assassinato de uma atriz da rede Globo, o que merece respeito humano, mas a peça legislativa não atacou o cerne de nenhum problema social ou econômico do País. As duas leis referentes ao mundo da política o abordam da estrita perspectiva ética, menos que isso aliás: reduzem-na ao tema da corrupção. Aliás, a Lei da Ficha Limpa suscitou um interessante questionamento: não estaria substituindo o eleitor pelos tribunais, fazendo-os tutelar o cidadão que, nas eleições, deveria ser soberano ${ }^{44}$ ? Quanto ao plebiscito de 1993 e ao referendo de 2005, foram duas lástimas. Depois de um século de regime republicano, perguntar ao eleitor se quer a monarquia de volta, sem nenhuma base popular, foi uma decisão interna à Constituinte, sob

\footnotetext{
42 Na ordem cronológica: 1) Lei 8.930 de 7 de setembro de 1994, inclui novos crimes entre os hediondos; 2) Lei 9840, de 28 de setembro de 1999, cassa mandato de eleitos que tenham comprado votos; 3) Lei 11.124, de 16 de junho de 2005.sobre habitação popular; 4) Lei Ficha Limpa, ou Lei Complementar $n^{\circ} .135$ de 2010, 4 de junho de 2010, torna inelegíveis políticos condenados em decisões colegiadas de segunda instância.

$43 \mathrm{O}$ plebiscito quanto à monarquia teve um caráter quase folclórico, expresso por sinal na enorme vantagem que sobre esse regime teve a república. Já a segunda questão submetida ao povo foi mais séria.

44 Simplificando, a principal determinação desta lei é que, se um candidato tiver sido condenado em duas instâncias, fica proibido de concorrer às eleições.
} 
pressão do único deputado monarquista que dela fez parte. O mesmo plebiscito incluiu uma questão mais séria, a do parlamentarismo, mas sem nenhuma mobilização da sociedade: seu resultado apenas tornou ainda mais difícil uma eventual adoção dessa forma de governo, no futuro. Por sinal, o único plebiscito anterior da história brasileira, em 1963, já tinha rejeitado esse regime, o que torna imoral qualquer ideia de implantá-lo sem uma nova consulta popular (embora, de tempos em tempos, os setores mais conservadores o proponham como solução para alguma crise política). Finalmente, em 2005, com tantos assuntos que poderiam ir às urnas, como o direito ao aborto, levar a elas a proibição da venda de armas - também sem mobilização popular - era caminhar para uma derrota garantida. Todas essas consultas diretas se deram sem galvanizar a sociedade. Falharam justamente em seu propósito, a democracia direta.

Duas outras experiências foram mais bem-sucedidas, fora do âmbito eleitoral. A primeira foi o Orçamento Participativo, concebido e implantado por Tarso Genro, quando prefeito de Porto Alegre pelo Partido dos Trabalhadores, em 1989. A iniciativa teve ampla repercussão, sendo adotada em outros estados e países, graças em boa parte ao Fórum Social Mundial, que o mesmo prefeito iniciou em Porto Alegre e durante vários anos constituiu um desafio explícito ao Fórum Econômico Mundial que se reúne anualmente em Davos, na Suíça ${ }^{45}$. Trata-se de convidar movimentos, e mesmo indivíduos interessados, para o debate em plenárias divididas por região ou por assunto, sobre como serão alocados os investimentos (ou parte deles) no orçamento municipal. Esse procedimento causou atritos com os vereadores, mas seu objetivo era justamente ter uma participação mais ativa dos cidadãos. Tornou-se uma bandeira do PT, nos anos anteriores a sua vitória na eleição presidencial de 2002, mas

45 A obra de referência sobre o tema é AVRITZER e NAVARRO -. A inovação democrática no Brasil: o orçamento participativo. Um resumo e estudo da mesma se encontra em "O orçamento participativo revisitado", de Jussara Reis Prá. 
não teria como ser aplicado em escala federal, e talvez por isso declinou em importância nos anos seguintes.

A outra experiência, fartamente empregada já no governo federal, foram conferências nacionais, tematizadas por assunto, que com ampla representação dos movimentos diretamente interessados se reuniam em Brasília, para definir políticas públicas de teor social. Permitiam a formulação dessas políticas de acordo com as demandas, estruturavam uma rede capilarizada de formuladores, defensores e às vezes implantadores dessas políticas, e por isso mesmo despertaram críticas na oposição, que as acusava de eleitoreiras. É significativo que, apenas três dias após a reeleição da presidenta Dilma Rousseff, que se deu a 26 de outubro de 2014, a Câmara de Deputados tenha aprovado decreto legislativo derrubando o decreto presidencial 8243, de 23 de maio do mesmo ano, o qual consolidava o sistema de consultas e conferências à sociedade ${ }^{46}$. Argumentou-se no Congresso que o decreto presidencial afrontava o sistema representativo. Não está errado, mas já lembramos que pela Constituição a democracia brasileira não é só representativa - tendo também uma dimensão direta, exatamente aquela que as conferências pretendiam.

O aumento na participação popular foi interpretado diferentemente pelos dois lados em confronto na política brasileira. Para a esquerda, foi um avanço democrático, realizando um preceito constitucional, além de seu mérito, digamos técnico, que consistia em capilarizar a definição e implementação de políticas públicas, tornando-as melhores e mais eficazes. Para a direita, era um aparelhamento do Estado pelo partido no governo, com alguns extremistas falando até mesmo em regime bolivariano ou soviético. É pena que o PSDB tenha abandonado o projeto de um de seus principais fundadores, o falecido governador Franco Montoro, que insistia na necessidade de uma democracia "participativa", indo adiante da representativa, embora não fosse uma democracia direta.

46 O Senado não deliberou a respeito, de modo que o decreto continuou em vigor. 
$\mathrm{Na}$ verdade, nem as conferências dos governos petistas eram exemplos de democracia direta. Eram, sim, de democracia participativa.

O PT pode ter sido acusado de aparelhar o Estado, mas na verdade os partidos são fracos no Brasil, a despeito de vários instrumentos legais que em tese os fortaleceriam. A legislação proíbe a candidatura de quem não esteja filiado a uma agremiação um ano antes do pleito (em 2016, o prazo caiu para seis meses), de modo que surpresas de última hora ficam praticamente impossíveis. Não são permitidas candidaturas avulsas. Os partidos recebem financiamento público; alguns analistas entendem que certos candidatos à presidência, obviamente inviáveis, se apresentam só para garantir o dinheiro para seu partido ou seu grupo. Os partidos têm força legal, mas nem tanto no plano político.

No presidencialismo brasileiro, os cargos propriamente políticos que há fora do Executivo se tornaram um indesejável prêmio de consolação. Ser presidente do partido ou seu líder, ou mesmo líder do governo, numa das Casas do Congresso é de magro apelo, na comparação com um ministério qualquer, mesmo um de poucas verbas ou de rara aparição na mídia. Se isto vale para o lado do governo, do lado das oposições - que teriam interesse em desenvolver um shadow cabinet ${ }^{47}$ - ocorre o mesmo ou até pior. $\mathrm{O}$ candidato do PSDB às presidenciais de 2014 sempre apareceu pouco no Senado e perdeu muitas oportunidades de se revelar como líder. Já a terceira força que se destacou em 2010 e 2014 calou-se depois dessas duas eleições, com a candidata Marina Silva não aproveitando o espaço que a mídia lhe oferecia para definir as políticas de seu atual partido, a Rede Sustentabilidade. Resultado desse vazio político das duas oposições foi, na turbulência política brasileira de 2015-16, o PMDB - que esteve dez anos no governo petista - acabar ganhando a presidência e muitos ministérios, um partido que apesar de grande se caracteriza pela falta de projetos.

47 O PT criou um depois de perder a eleição de 1994, mas jamais funcionou de fato. 
O esvaziamento político dos partidos, a fraqueza dos líderes que não têm cargo ou verbas e em especial dos que estão no Legislativo desenha um quadro em que a atuação política cabe a indivíduos ou pequenos grupos. Até isso diminuiu nos anos de governo do PT, porque muitos líderes ativos e intensos assumiram cargos no governo; seus movimentos perderam luz própria, alguns deles tendendo a funcionar um pouco como apêndices do poder. As manifestações de 2013 e as de 2015, pese sua enorme diferença, atestam esse fato - antes de mais nada porque, pela primeira vez em trinta anos, as ruas não eram do PT mas contra ele. Em 2013 os protestos começaram conduzidos por pequenos grupos à esquerda do governo, os quais perderam sua liderança depois que a violência policial multiplicou a quantidade e ensejou a mudança na qualidade das manifestações. Já em 2015, quando o foco dos protestos do dia 15 de março esteve à direita, esta se expressou sem líderes, o que pode explicar, ou não, a presença vistosa de defensores da volta do regime militar. Nos dois casos, porém, temos o esvaziamento das organizações, partidárias ou não, somado à desorganização das mentes, que dificilmente conseguem esboçar um projeto consistente para a sociedade.

Não é à toa que o Brasil ora vive uma crise grave de sua policy: nem organizados nem desorganizados vislumbram uma saída para ela - o que só piorou depois do impeachment de Dilma, porque o número de possíveis indiciados por corrupção cresceu exponencialmente, sendo a maior parte deles líderes da nova coalizão de governo. Não há sinal também de que surjam nomes significativos para disputar a Presidência da República; é verdade que Lula é o candidato mais forte segundo as pesquisas, mas ele é o líder incontestado do PT desde 1982. Mesmo em caso de vitória sua, ela expressará a dificuldade de seu partido, como dos outros, para gerar líderes novos. Estão em crise os dois grandes braços da democracia representativa - a representação dos mais pobres e discriminados e a governabilidade. Os partidos hoje têm menos peso, aqui, do que se imagina. 
Já na América do Sul como um todo, a esquerda que nos últimos dez anos governou vários de seus países entrou em crise. Tomemos Teodoro Petkoff, o ex-guerrilheiro do Movimento al Socialismo que depois se moderou e se tornou o principal ministro do presidente Rafael Caldera, o último governante da Venezuela antes do chavismo. Em seu prefácio a Chávez sin uniforme (2005), possivelmente a mais equilibrada biografia do falecido presidente, ele é um dos primeiros a distinguir na região uma esquerda radical e não-democrática, que dirigiria a Venezuela, a Bolívia e o Equador, bem como talvez a Argentina, de outra moderada e democrática, tendo por expoentes Lula (depois, Dilma) no Brasil e Michelle Bachelet no Chile. Ora, vários desses líderes perderam o governo para a direita, em eleições na Argentina ou pelo processo controverso de impeachment no Brasil.

Ter-se-á chegado ao limite das políticas de inclusão social? Não haverá mais como financiá-las no estado atual das economias nacionais? Estará caindo o amor pela democracia? Estas questões não podem ser respondidas no momento atual, mas são hoje as mais importantes para o regime democrático. Na verdade, merecem resposta mais no plano da ação do que no da pergunta; é menos uma questão de análise que de luta; precisamos retomar a tendência de democratização crescente das sociedades do mundo inteiro.

\section{Bibliografia}

AVRITZER, Leonardo e NAVARRO, Zander (orgs.) - A inovação democrática no Brasil: o orçamento participativo. São Paulo: Cortez, 2003.

ECONOMIST INTELLIGENCE UNIT - Democracy Index 2014: Democracy and its discontents, consultado em 13 de março de 2017. Disponível em http://www. sudestada.com.uy/Content/Articles/421a313a-d58f-462e-9b24-2504a37f6b56/ Democracy-index-2014.pdf.

ECONOMIST INTELLIGENCE UNIT - Democracy Index 2016 Revenge of the "deplorables", consultado em 13 de março de 2017. Disponível em http://pages. eiu.com/rs/783-XMC-194/images/Democracy_Index_2016.pdf. 
HUNTINGTON, Samuel - A Terceira Onda: A Democratização no Final do Século $X X .1^{a}$ edição. São Paulo: Ática, 1994.

JANINE RIBEIRO, Renato - "Brazil and the democracy of protest". In Post-Regionalism in the Global Age: Multiculturalism and Cultural Circulation in Asia and Latin America. Rio de Janeiro: Educam, 2014, disponível em http:// www.alati.com.br/pdf/2014/malaysia/parte-6_-_Renato-Janine-Ribeiro.pdf; e sua tradução para o português, "O Brasil e a democracia de protesto". In Matrizes, vol. 8 (1), 2014, disponível em http://www.revistas.usp.br/matrizes/article/view/82933/85969, ambos consultados em 13 de março de 2017.

JANINE RIBEIRO, Renato - "Eleições 2014 A Quarta Agenda da Democracia Brasileira (Ou: o que 2013 Trouxe)". In Interesse Nacional, ano 7 (25), 2014. Consultado em 13 de março de 2017, disponível em http://interessenacional. com/index.php/edicoes-revista/eleicoes-2014-a-quarta-agenda-da-democracia-brasileira-ou-o-que-2013-trouxe/.

PRÁ, Jussara Reis - "O orçamento participativo revisitado". In Revista de Sociologia e Politica, vol. 21, Curitiba, 2003. Consultado em 13 de março de 2017. Disponível em http://www.scielo.br/scielo.php?pi$\mathrm{d}=$ S0104-44782003000200013\&script=sci_arttext

SOUZA, Jessé - "A Cegueira do Debate Brasileiro sobre as Classes Sociais". In Interesse Nacional, ano 7 (27), 2014. Consultado em 13 de março de 2017, disponível em http://interessenacional.com/index.php/edicoes-revista/a-cegueira-do-debate-brasileiro-sobre-as-classes-sociais/.

TELlES, Mara - Perfil Ideológico e Atitudes Políticas dos Manifestantes. Belo Horizonte, 12 de abril de 2015. Power point. Consultado em 13 de março de 2017. Disponível em https://drive.google.com/file/d/0B1_d2uNS-ZSvMHpUZ01fOTBLMWc/view?pli=1.

TYSZKA, Alberto Barrera e MARCANO, Cristina - Hugo Chávez sin uniforme: una historia personal. Caracas: Debate, 2004. 